Article

\title{
The Cross-Level Effect of Shared Leadership on Tourism Employee Proactive Behavior and Adaptive Performance
}

\author{
Hui Fu ${ }^{1}$, Ben Haobin Ye ${ }^{2, *}$ and Xiaoyu $X u^{1}$ \\ 1 Business School, Sun Yat-sen University, No. 135, Xingangxi Rd., Guangzhou 510275, China; \\ mnsfuh@mail.sysu.edu.cn (H.F.); xuxiaoyu31@crland.com (X.X.) \\ 2 School of Tourism Management, South China Normal University, Higher Education Mega Center, \\ Guangzhou 510006, China \\ * Correspondence: ben_ye@m.scnu.edu.cn
}

Received: 10 July 2020; Accepted: 24 July 2020; Published: 31 July 2020

\begin{abstract}
Shared leadership has emerged as a new style that has been proven to contribute to employee performance. However, the underlying mechanism of shared leadership on employee performance and its possible correlates have not received sufficient academic attention in the literature. To narrow the related research gaps, the current study aims to establish a multi-level framework incorporating shared leadership, team reflexivity and employee performance, and examined the cross-level mediation mechanism between shared leadership and adaptive performance. A questionnaire survey consisting of 301 valid employees' samples from 31 work teams in the hotel industry in China validated the proposed model. Multilevel analysis with Mplus was applied. The current study found that shared leadership positively influences team reflexivity, and share leadership influences employee's adaptive performance through proactive behavior. The current study sheds light on the role of shared leadership in tourism organizations. The practical implications regarding how to improve the organizational environment to enhance productivity are further discussed.
\end{abstract}

Keywords: shared leadership; proactive behavior; adaptive performance; team reflexivity

\section{Introduction}

With the slowdown of global economic growth, external opportunities for tourism organization operators to explore are relatively limited. Managers are keen to maximize the value of internal resources. As the human capital of an organization is flexible resources [1], tourism managers can implement the most effective leadership style to motivate employees' positive behavior and improve their job performance. The literature on shared leadership has proliferated over the last decade [2-7]. Shared leadership refers to the distribution of leadership influence among organizational members [2]. Prior studies indicate that shared leadership contributes to employees' learning capability [8], team process [9], and firm performance [2,10]. Although scholars in recent decades have started to examine the antecedents and consequences of shared leadership (e.g., Carson et al., Ensley et al.) [2,5], limited research has been conducted on its potential impacts on team capability, employee behavior and performance in hospitality research. In addition, the underlying mechanism that molds the relationship between shared leadership and employee performance has been largely under-researched.

Shared leadership can boost an organizational learning climate in which members learn from each other to improve work effectiveness. However, prior research has not paid sufficient attention to the nature of team learning - that is, how the team improves learning. Hence, team reflexivity can be appropriately applied to illuminate how shared leadership can affect team learning. In particular, team members can be encouraged to openly reflect and communicate on team goals, strategy, and process 
to achieve a better fit for current or expected situations [11], which can undoubtedly enhance team decision making quality and, thus, performance outcomes. Although prior research has examined the relationship between vertical leadership and team reflexivity (e.g., Schippers, Den Hartog, Koopman, and van Knippenberg) [12], an investigation into the influence of shared leadership on team reflexivity has been limited.

While prior research mainly focuses on traditional measures of work outcomes as the consequences of shared leadership $[9,13]$, the current study considers relatively novel measures namely proactive behavior and adaptive performance. In a fiercely competitive and dramatically changing environment, employees need to be proactive at work [14]. Proactivity is believed to benefit the current and future development of organizations [15]. An uncertain working environment also requires employees to constantly update their skills and knowledge, to solve problems with creative thinking, to be flexible in coping with human relations, and to be adaptive to different corporate cultures. The current study examines the consequences of shared leadership by focusing on proactive behavior and adaptive performance.

To narrow the aforementioned research gaps, the current study aims to reveal the effect of shared leadership that has on team reflexivity (team level) and employee proactive behavior and adaptive performance (individual level), and the mediating role of employee proactive behavior was also examined.

\section{Literature Review}

\subsection{Shared Leadership}

Shared leadership was introduced in the 1980s, as were similar concepts such as collective leadership and distributed leadership. The essence of these concepts is the distribution of leadership and shared responsibility among organizational members. Numerous definitions of shared leadership have been developed in the past decades $[2,5,10,16-18]$. A review of the definitions reveals the essential features of shared leadership. First, shared leadership implies distributed power and responsibility among organizational members [13]. Second, shared leadership is dynamic in nature, and leadership roles are contingent on the task nature and organizational members' different capabilities [19]. When tasks are routine-based, shared leadership may be reduced. In contrast, shared leadership may be enhanced when shared mindsets are needed in some situations [3]. Third, shared leadership enables open boundaries: instead of being confined to a few persons, leadership roles can be assumed by numerous organizational members [2,5]. The boundary in vertical leadership does not exist in shared leadership [20]. Fourth, shared leadership and vertical leadership are not mutually exclusive and can coexist. In addition, the former can complement the latter [20]. For the purpose of the current study, shared leadership is defined as power and responsibility distributed among employees within hospitality organizations.

It is likely that employees who have high power distance cultural orientation may be more prone to embrace leaders' ideas and more reluctant to accept leadership responsibility [21]. One may cast doubts on the existence of shared leadership in countries characterized by high power distance cultural orientation such as China. However, it is argued that shared leadership does not contradict the external leadership hierarchy [22]. Carson et al. [2] echo this view by asserting that the external leadership hierarchy can still play a role. Recent studies also reveal that shared leadership is prevalent in R\&D teams in Japan, which features high power distance [23,24]. Similarly, it is plausible that shared leadership can play important roles in Chinese organizations as well.

\subsection{Consequences of Shared Leadership}

Prior research generally found that shared leadership can bring with favorable organizational outcomes. They include employee's sense of belonging, learning capability, job satisfaction, commitment [8], team process and emergent states [9], organizational commitment, collective 
psychological capital, and creativity [7] and firm performance [2,10]. Pearce and Conger [10] argue that the two distinct features of shared leadership are shared leading responsibility and mutual influence among organizational members. Hence, shared leadership may exert its influence on the team environment, team members' behavior, and team performance. For team members' behavior, shared leadership allows members to demonstrate their ability and contributions to their organizations, thus enhancing their sense of belonging, learning ability through the process of leading and being led [8], mutual trust through cooperation and mutual support [25], psychological security to voice ideas [26], and job satisfaction and job commitment [2,27]. At the team level, shared leadership is found to influence team trust $[9,28]$ and team cohesiveness [13]. Shared leadership is also found to positively affect team performance [2].

\subsection{Proactive Behavior}

Some traditional management theories such as goal-setting theory and equity theory view employees as reactive and environmentally responsive [29]. Nevertheless, a number of studies have shown that employees can set goals on their own and provide self-incentives that enhance their job performance [30-32]. Such employees' initiative leads to the introduction of new concepts of employee performance. For example, proactive behavior in work settings refers to individuals' initiatives to take over control of events. The concept focuses on proactive behavior that facilitates the transformation of the environment and the self [32]. The characteristics of proactive behavior include being self-starting, change-oriented, and future-focused [33].

Prior research offers some indications that shared leadership can influence proactive behavior. Shared leadership enables a supportive environment in which employees are motivated to co-lead the team and mutually influence each other toward a common goal. In such an environment, team trust [34] and employees' sense of belonging [8] are developed, which nurturing employees' feelings of a safe and free work environment where they do not need their supervisors' instructions to take proactive actions.

According to social exchange theory, when people receive benefits from others, he or she will be inclined to give back to strengthen the mutual relationship (reciprocal reinforcement) (Blau,1964) [35]. In the organizational context, the theory has been widely applied to explain the relationship between subordinates and their supervisor [36-38]. When employees receive economic and emotional benefits from the organization, they are more inclined to repay the organization by engaging more in their work, devoting more efforts to improve their work performance. Prior research suggests that the ongoing reciprocal exchange between employees and organizations can explain employees' work performance [39]. In the shared leadership context, it is plausible that the team-member exchange generates positive employee behavior. Prior research suggests that such a positive team-member relationship can facilitate employees' internalization of team goals and engender proactive behavior [33]. In particular, shared leadership provides signals that the organization trusts the employees' capability to lead the team. These entrusted and empowered employees may increase their proactive behavior to reciprocate their teams [40]. They may actively set their job goals, anticipate possible changes, and take a future perspective on their job then show more proactive actions. Hence, we propose the following hypothesis:

Hypothesis 1 (H1). Shared leadership positively influences proactive behavior.

\subsection{Adaptive Performance}

Management scholars have advocated for a deeper understanding of the dynamic nature of employee performance in uncertain and ambiguous environments [41]. A dynamic external environment may challenge employees' skills and knowledge and require them to react or make necessary changes in a timely manner. Adaptive performance refers to all types of behavior that employees use to cope with expected and unexpected transformations at work, and such behavior is 
instrumental for organizational development and productivity enhancement. Adaptive performance may arise when employees need to change work roles or learn new skills [42], and such anticipatory behavior can reduce job decrements [41]. Adaptive performance is also important in the hospitality industry as employees may need to learn new skills and knowledge to cope with the latest development in technology. For example, employees may need to learn new relationship management skills or software to engage and satisfy their customers (e.g., social media posting, virtual reality equipment, etc.).

Griffin, Neal, and Parker [43] find that team support and organizational commitment affect adaptive performance. In addition, research has revealed that some leadership styles result in an adaptive performance. For example, when employees are open to job role changes, visionary leaders can help them enhance self-rated adaptive performance [44]. Transformational leaders can also enhance employees' adaptive performance by changing the work atmosphere [45]. In line with these studies, we propose that shared leadership can influence adaptive performance. First, employees' learning capabilities are developed through the processes of leading and being led [8], resulting in higher self-efficacy and adaptive performance $[46,47]$. Second, the equal, cooperative, and supportive environment induced by shared leadership facilitates perceived team support. When employees feel that they receive sufficient support from the organization, their adaptive performance can be enhanced [44].

Employees under shared leadership feel that they are empowered to lead and influence their teams and thus tend to perceive more support from the organizations. According to social exchange theory, they may show more job commitment and more greatly enhance their proactive behavior to reciprocate their organizations. In particular, they may not passively perform tasks assigned by their supervisors or required by their jobs, but rather proactively think of new and/or efficient ways to better accomplish tasks under changing environment. In addition, as an employee, proactive behavior is self-starting, change-oriented, and future-focused in nature [33], it can be expected that such behavior can lead to better coping with uncertainties at work (i.e., adaptive performance). In particular, employees may already anticipate changes in customer demand and/or technological innovations in their organizations and make better preparations in advance. In sum, it is plausible that shared leadership triggers employees' proactive behavior which in turn enhances their adaptive performance. Hence, the following hypotheses are proposed:

Hypothesis 2 (H2). Proactive behavior positively influences adaptive performance.

Hypothesis 3 (H3). Shared leadership indirectly influences adaptive performance through proactive behavior.

\subsection{Shared Leadership and Team Reflexivity}

Individuals are susceptible to environmental influences when they make decisions and take actions [48]. The social cognitive theory [49] can, therefore, be appropriately applied in the current research context. The theory deals with how individuals acquire knowledge by observing others through social interactions and experience. People learn by emulating role models in different social contexts. Social cognitive theory [49] identifies social cognitions as individuals' perceptions of others, groups, and themselves. The cognition process requires one to analyze information according to past experience and relevant cues. A leader's behavior or leadership style can serve as environmental cues that are available for employees' cognition processes. Team leaders can exert their influences on the work environment where employees form perceptions about their team and organization and take subsequent actions. Prior research found that transformational leadership, authentic leadership, and intra-team trust can exert influence on team reflexivity [12,50]. Hence, it is likely that shared leadership influences the environment in which employees make decisions, resulting in their behavioral changes.

Team reflexivity refers to team members openly reflecting and communicating on team goals, strategy, and process to achieve a better fit for current or expected situations [11]. Reflection, planning, and action are considered key to team reflexivity. Team reflexivity was found to contribute to team 
innovation [51] and team performance [12,50]. In the context of a volatile external environment, it is important for firms to constantly reflect on their goals and strategies and respond promptly to the changing environment.

It is likely that shared leadership affects team reflexivity. The underlying reasons are as follows. First, shared leadership enables employees' knowledge sharing [8], interaction, and cooperation [13]. Thus, employees can obtain the necessary knowledge and skills to enable them to make better reflections then take more effective actions. Second, mutual influence and support encourage employees to solve problems with cooperation and collective reflections [52] and facilitate the emergence of team reflexivity. Third, mutual trust that is derived from shared leadership facilitates discussion and reflections in teams [53], rendering more appropriate subsequent actions. Therefore, it is hypothesized that:

Hypothesis 4 (H4). Shared leadership positively influences team reflexivity.

The research model of our study, encompassing all of the hypothesized paths, is depicted in Figure 1.

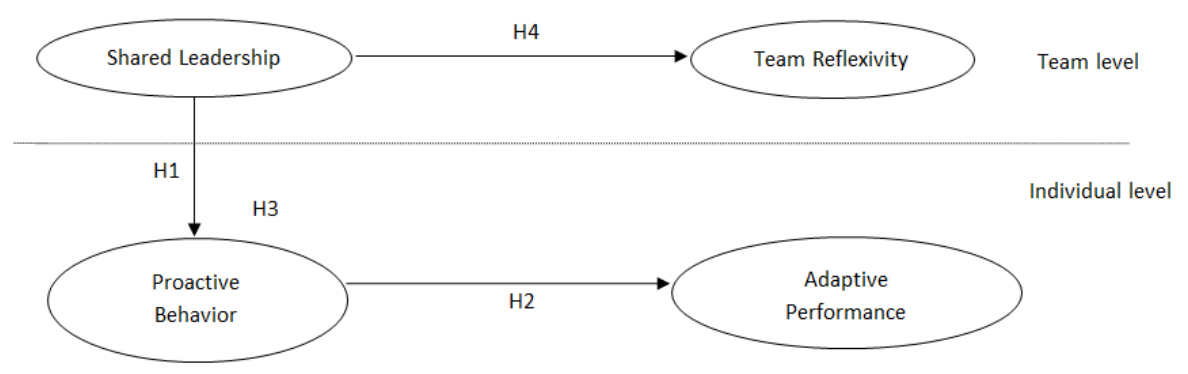

Figure 1. Research Model

\section{Methodology}

\subsection{Sample and Procedure}

The participants of the current study are employees from the hotel industry in Guangzhou, China. The hotel industry in China was chosen as the context of the study mainly for two reasons. First, China ranks second in terms of GDP among all nations and China has an enormous and booming tourism market. According to the official statistics, there are 12,213 star-rating hotels in China in the fourth quarter of 2016 (China National Tourism Administration, 2017). Second, China is characterized by collectivistic and high-power distance cultural orientation [23]. It will be interesting to examine whether or not shared leadership exerts its effects on employee behavior and performance in a non-western context where traditional leadership (i.e., authoritarian leadership) dominates.

The data was collected from the staff of different departments in the hotel industry in Guangzhou city in Southern China. The questionnaires were distributed to general staff and front-line staff from different departments by staff from the human resource management departments. The respondents include employees and their supervisors (e.g., front-line managers), covering 31 work teams, and the average team size is 10 employees. Respondents were briefed about the purpose of the survey before they completed the questionnaires. We applied a number of procedures to ensure the reliability of the survey. For example, to minimize social desirability bias, respondents were ensured that their colleagues would not be able to read their answers because they would be sealed in envelopes for our academic purpose. To reduce common method variance, the questionnaire items were counterbalanced. In addition, Harman's one-factor test indicated common method variance is not a major issue. Particularly, six factors emerged from the factor analysis, accounting for $63.9 \%$ of the total variance, and the first factor only explains $14 \%$ of the total variance. Of the 450 questionnaires that were distributed, 301 valid questionnaires were returned, resulting in a response rate of $67 \%$. The data were then processed using AMOS17.0, SPSS22.0, and Mplus 7.0. In our study, shared leadership and team 
reflexivity were treated as team level constructs and proactive behavior and adaptive performance are treated as individual-level constructs. Thus, Mplus, which is a powerful tool to examine cross-level relationships among constructs, was used to test the model.

- Compliance with Ethical Standards: All procedures performed in studies involving human participants were in accordance with the ethical standards of the institutional and/or national research committee and with the 1964 Helsinki Declaration and its later amendments or comparable ethical standards.

- Informed Consent: Informed consent was obtained from all individual participants included in the study.

\subsection{Measures}

The measurement scales of the survey were adapted from prior research. The reliability and validity of these scales have been well proven. A 5-point Likert-scale was used ranging from "strongly disagree $=1$ " to "strongly agree $=5$." To measure shared leadership, Hoch and Kozlowski's [6] three-dimensional scale was used. These dimensions are team learning (4 items), perceived team support (5 items), and team-member exchange (7 items). Sample items are "To improve job performance, members can evaluate each other's work" (team learning), "Our team values members' contribution to the department's welfare" (perceived team support), and "Our team will use authority to help members solve critical problems encountered" (team-member exchange). Team reflexivity was measured by the 5-item scales from De Jong and Elfring [53]. A sample item is "In this team, we regularly discuss whether we are working effectively together." Proactive behavior and adaptive behavior were measured by the 6-item scales from Griffin, Neal, and Parker [43]. Sample items are "I come up with ideas to improve the way in which my core tasks are done." for proactive behavior, and "I learned new skills to help me adapt to changes in your core tasks." for adaptive performance. The items were translated into Chinese, and back-translation by a researcher who is proficient in both English and Chinese was used to ensure accuracy [54]. A pilot study was conducted to ensure the validity of the questionnaire. Only minor changes in wording were made. (please refer to Appendix A)

\section{Findings}

\subsection{Descriptive Statistics}

The sample consisted of slightly more male (54.5\%) than female (45.5\%). Staff under the age of 30 comprises half of the sample, followed by those aged between $30-39(23 \%)$, and those aged $40-49$ $(20.4 \%)$. Slightly more than $70 \%$ of the respondents had received the high school of below education and less than $10 \%$ of the respondents received university or above education. The demographics of the respondents are summarized in Table 1.

Table 1. The demographics of respondents.

\begin{tabular}{cccc}
\hline Variable & Category & Frequency & \% \\
\hline \multirow{2}{*}{ Gender } & Male & 164 & 54.5 \\
& Female & 137 & 45.5 \\
& Under 30 & 72 & 23.9 \\
Age & $30 \sim 39$ & 105 & 34.9 \\
& $40 \sim 49$ & 85 & 28.2 \\
& 50 or above & 39 & 13 \\
\multirow{4}{*}{ Education } & High school or below & 154 & 51.2 \\
& Higher diploma & 94 & 31.2 \\
& Bachelor degree & 52 & 17.3 \\
& Master degree or above & 1 & 0.3 \\
& General staff & 189 & 62.8 \\
& Front-line manager & 112 & 37.2 \\
\hline
\end{tabular}




\subsection{Reliability and Validity}

The reliability of all of the constructs was tested and verified using both Cronbach's alpha and composite reliability. First, the unidimensionality of the measurements was established by confirmatory factor analysis, which revealed that the data fit the measurement model well [55]. The Cronbach's alphas of all of the constructs surpassed the satisfactory level of 0.70 , ranging from 0.75 to 0.91 . In addition, the composite reliability surpassed the acceptable level of 0.50 , ranging from 0.75 to 0.88 [56] (See Table 2 for details).

Table 2. Results of Confirmatory Factor Analysis.

\begin{tabular}{|c|c|c|c|c|c|}
\hline Construct & Item & $\begin{array}{l}\text { Standardized } \\
\text { Loading }\end{array}$ & $\begin{array}{c}\text { Cronbach's } \\
\text { Alpha }\end{array}$ & $\begin{array}{l}\text { Composite } \\
\text { Reliability }\end{array}$ & $\begin{array}{c}\text { Average Variance } \\
\text { Extracted }\end{array}$ \\
\hline \multirow{15}{*}{ Shared Leadership } & SL1 & 0.763 & \multirow{15}{*}{0.91} & \multirow{3}{*}{0.79} & \multirow{3}{*}{0.56} \\
\hline & SL2 & 0.714 & & & \\
\hline & SL3 & 0.764 & & & \\
\hline & SL5 & 0.551 & & \multirow{6}{*}{0.86} & \multirow{6}{*}{0.52} \\
\hline & SL6 & 0.696 & & & \\
\hline & SL7 & 0.743 & & & \\
\hline & SL8 & 0.746 & & & \\
\hline & SL9 & 0.776 & & & \\
\hline & SL10 & 0.769 & & & \\
\hline & SL11 & 0.683 & & \multirow{6}{*}{0.86} & \multirow{6}{*}{0.51} \\
\hline & SL12 & 0.716 & & & \\
\hline & SL13 & 0.753 & & & \\
\hline & SL14 & 0.734 & & & \\
\hline & SL15 & 0.704 & & & \\
\hline & SL16 & 0.694 & & & \\
\hline \multirow{5}{*}{ Team Reflexivity } & TR1 & 0.675 & \multirow{5}{*}{0.85} & \multirow{5}{*}{0.84} & \multirow{5}{*}{0.52} \\
\hline & TR2 & 0.761 & & & \\
\hline & TR3 & 0.758 & & & \\
\hline & TR4 & 0.723 & & & \\
\hline & TR5 & 0.669 & & & \\
\hline \multirow{3}{*}{ Proactive Behavior } & P1 & 0.739 & \multirow{3}{*}{0.76} & \multirow{3}{*}{0.76} & \multirow{3}{*}{0.52} \\
\hline & P2 & 0.691 & & & \\
\hline & P3 & 0.732 & & & \\
\hline \multirow{3}{*}{ Adaptive Performance } & A1 & 0.728 & \multirow{3}{*}{0.75} & \multirow{3}{*}{0.75} & \multirow{3}{*}{0.51} \\
\hline & $\mathrm{A} 2$ & 0.726 & & & \\
\hline & A3 & 0.679 & & & \\
\hline
\end{tabular}

(Note: item SL1 to SL3 measure Team Learning, item SL5 to SL 10 measure Perceived Team Support, item SL 11 to

SL 16 measure Team-member Exchange).

Second-order confirmatory factor analysis (CFA) was used to validate the dimensions of shared leadership. All of the measurement items were loaded on their expected constructs, whose factor loading scores were all greater than 0.5 . The three factors loaded on shared leadership significantly, with factor loadings of 0.586 (team-member exchange), 0.936 (perceived team support), and 0.867 (team learning). The model indices provided a good fit, with $X^{2}(101)=197.339, X^{2} / d f=1.954$, root mean square error of approximation $($ RMSEA $)=0.056$, Standard root-mean-square residual $($ SRMR $)=0.0539$, and comparative fit index $(\mathrm{CFI})=0.956$ and the goodness of fit index $(\mathrm{GFI})=0.925$. These fit indices suggest that the model has a good fit (Hu \& Bentler, 1999). Another CFA was conducted with all of the constructs, the model fit was found to be satisfactory $\left(X^{2}(309)=572.998, X^{2} / d f=1.854\right.$, RMSEA $=0.053$, $\mathrm{SRMR}=0.0514, \mathrm{CFI}=0.929$, and GFI $=0.87$ ).

The average variance extracted (AVE) for all first-order factors surpassed the threshold value of 0.5 . Hence, we can conclude that all of the constructs of our study met the convergent validity criteria. In addition, the correlation coefficients of the research constructs were below 0.85 [57] 
(See Table 3). The AVEs were generally higher than the squared multiple correlations among different pairs of constructs, indicating that the research model had good discriminant validity reliability [55,58]. Although the correlation between team member exchange and perceived team support was slightly high (0.811), it was lower than the threshold value. These two factors were conceptually differentiated.

As shared leadership and team reflexivity are team-level constructs, we need to test the suitability for aggregation. We used the common indices ICC and Rwg for the test $[59,60]$. In particular, the ICC (1), ICC (2), and Rwg for shared leadership are $0.26,0.80$, and 0.96 respectively, and those for team reflexivity are $0.31,0.83$, and 0.95 . These statistics indicate suitability for aggregating team-level constructs of our study.

Table 3. Latent Variable Correlation Coefficients.

\begin{tabular}{ccccccc}
\hline & $\begin{array}{c}\text { perceived } \\
\text { Team Support }\end{array}$ & $\begin{array}{c}\text { Team } \\
\text { Learning }\end{array}$ & $\begin{array}{c}\text { Team-Member } \\
\text { Exchange }\end{array}$ & $\begin{array}{c}\text { Adaptive } \\
\text { Performance }\end{array}$ & $\begin{array}{c}\text { Proactive } \\
\text { Behavior }\end{array}$ & $\begin{array}{c}\text { Team } \\
\text { Reflexivity }\end{array}$ \\
\hline $\begin{array}{c}\text { perceived team } \\
\text { support }\end{array}$ & - & & & & & \\
$\begin{array}{c}\text { Team Learning } \\
\text { Team-member }\end{array}$ & 0.549 & - & & & & \\
$\quad \begin{array}{c}\text { Exchange } \\
\text { Adaptive }\end{array}$ & 0.811 & 0.51 & - & & & \\
Performance & 0.576 & 0.457 & 0.624 & - & & \\
$\quad$ Proactive & 0.516 & 0.34 & 0.591 & 0.463 & - & \\
$\begin{array}{c}\text { Behavior } \\
\text { Team Reflexivity }\end{array}$ & 0.675 & 0.384 & 0.707 & 0.571 & 0.592 & - \\
\hline
\end{tabular}

\subsection{Hypothesis Testing}

Multilevel analysis with Mplus 7.0 was applied to test our hypotheses. Mplus is a powerful statistical software that can handle multi-level data. To ensure the scientific rigor of our study, we incorporate participants' age, gender, education, and job rank as control variables. The model fit is satisfactory with $X^{2} / d f=2.438, \mathrm{CFI}=0.928$, RMSEA $=0.069$. The hypothesized path between shared leadership and proactive behavior was significant $(B=0.655, p<0.05)$. The hypothesized path between shared leadership and team reflexivity was also significant $(B=0.871, p<0.01)$. The relationship between proactive behavior and adaptive performance is significant $(B=0.608, p<0.01)$. We compared different models. First, we added an additional path from team reflexivity to proactive behavior. The path is not significant $(B=0.071)$ and the model fit becomes worse $\left(X^{2} / d f=3.056, C F I=0.912\right.$, RMSEA $=0.083)$. Second, we added an additional path from team reflexivity to adaptive performance. Although the path is significant $(B=-0.693)$, but the negative coefficient does not make any sense, and the model fit $\left(X^{2} / d f=2.719, \mathrm{CFI}=0.926\right.$, RMSEA $\left.=0.076\right)$ does not improve. Hence, our proposed model best fits the data.

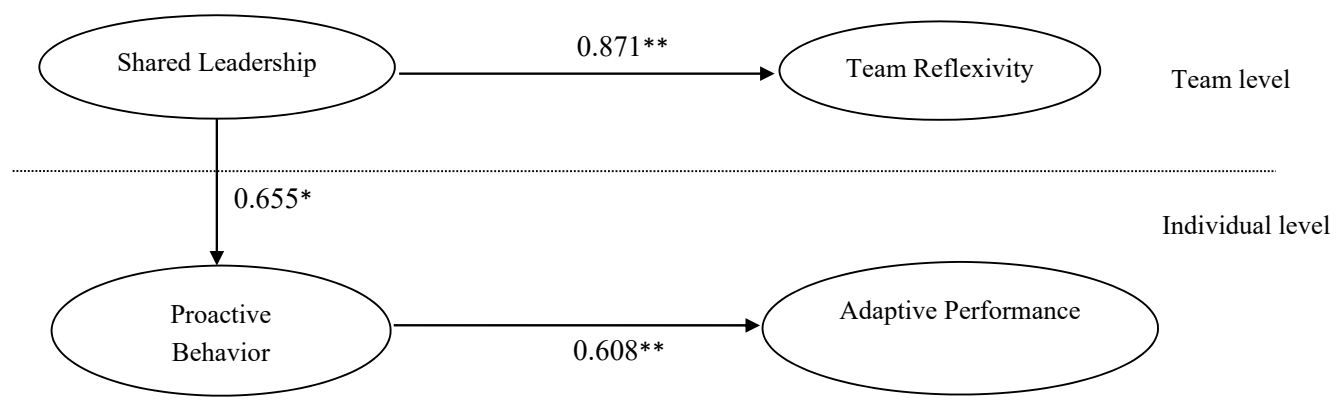

Figure 2. Results of the Model Testing. 
In addition, the mediation effect is significant $(B=0.394, p<0.05$, lower $5 \%=0.098$, upper $5 \%=0.69$ ). We added an additional path from shared leadership to adaptive performance, and the path is not significant $(B=0.218, p>0.05)$. The Chi-square test found a lack of significance $\left(X^{2} \mathrm{~d}(1)=0.75, p>0.05\right)\left(X^{2} / d f=2.719, \mathrm{CFI}=0.926\right.$, RMSEA $\left.=0.076\right)$ Therefore, we can claim that proactive behavior fully mediates such relationship [61].

The results of all of the path coefficients are shown in Table 4 and Figure 2. Hence, H1, H2, H3, and $\mathrm{H} 4$ were all supported (see Table 5).

Table 4. Summary of the Results.

\begin{tabular}{|c|c|c|c|}
\hline \multirow{2}{*}{ IndependentVariables } & Adaptive Performance & Team Reflexivity & Proactive Behavior \\
\hline & \multicolumn{3}{|c|}{ Estimate } \\
\hline \multicolumn{4}{|l|}{ Level 1} \\
\hline Study & -0.098 & & \\
\hline Gender & -0.099 & & \\
\hline Age & 0.039 & & \\
\hline Job & -0.109 & & \\
\hline Proactive behavior & $0.608^{* *}$ & & \\
\hline
\end{tabular}

\begin{tabular}{ccc} 
Proactive behavior & $0.608^{* *}$ & \\
\hline Level 2 & & \\
\hline Shared leadership & $0.871^{* *}$ & $0.655^{*}$ \\
\hline
\end{tabular}

Note: ${ }^{*} p<0.05$ (Two-Tailed). ${ }^{* *} p<0.01$ (Two-Tailed). $\mathrm{N}=301$ at individual level, $\mathrm{N}=31$ at team level.

Table 5. A summary of the results of hypotheses testing.

\begin{tabular}{ccc}
\hline Hypothesis & & Results \\
\hline H1 & Shared leadership positively influences proactive behavior. & Supported \\
H2 & Proactive behavior positively influences adaptive performance. & Supported \\
H3 & Shared leadership indirectly influences adaptive performance & Supported \\
H4 & through proactive behavior. & Shared leadership positively influences team reflexivity. \\
\hline
\end{tabular}

\section{Discussion}

The current study reaffirms the findings of the literature by demonstrating the cross-level and indirect effect of shared leadership on job performance $[9,13]$. The mutual influence among team members creates a supportive environment that improves employees' proactivity [40] thus enhances their adaptive performance [44]. The findings imply that shared leadership cultivates a supportive environment for communication among team members through leading and being led. Team members can thus feel safe to act proactively at work [8], leading in turn to their enhanced adaptive work performance [62]. Our findings are also congruent with $\mathrm{Wu}$ and Chen's [7] research which discovered the influence of shared leadership on positive psychological capital and organizational commitment in the hotel industry of Taiwan. In general, these findings are consistent in that shared leadership can engender positive employee's psychological state, leading to their performance improvement. Based on our study, it is safe to conclude that shared leadership in the hotel industry can also generate favorable organizational outcomes.

Shared leadership was found to contribute to team reflexivity which is congruent with the findings that leadership styles can influence team reflexivity [12,50]. Leaders' behaviors play a crucial role in shaping the work environment which may exert influence on their employees' behaviors at a team level. In the context of our study, it is likely that shared leadership develops trust among team members, and they may have more psychological safety to take initiatives. This, in turn, encourages them to openly discuss team goals and strategies. It is likely that leadership styles that can boost psychological safety and encourage open discussion may generate similar results as our study. Future research 
may consider investigating the underlying mechanism of such team level effect. Team trust and team psychological safety may be mediator candidates.

\subsection{Theoretical Implications}

Our study contributes to the literature in the following ways. First, we established a multi-level framework incorporating shared leadership, team reflexivity and employee performance, examined the cross-level mediation effect between shared leadership and adaptive performance, which have been largely ignored in previous research. In particular, proactive behavior and adaptive performance were examined to address the difficulties of measuring job performance in volatile work environments. Such new measures of job performance in the hospitality industry are deemed to more appropriately and comprehensively assess employees' work contributions. To the best of our knowledge, our study has pioneered the discovery that shared leadership contributes directly to employees' proactive behavior and indirectly to adaptive performance in leadership literature. These findings pave ways for future research on the effects of leadership styles on employees' behavior and employee performance. Future research can further investigate whether or not there are any boundary conditions. Second, we identified the underlying mechanism of how shared leadership influences employee job performance. Although prior research has found that shared leadership affects employees' learning capability [8] and team process [9], limited research efforts have been made to examine how shared leadership influences job performance through employee proactive behavior. Our research demonstrated that employee proactive behavior can fully mediate the relationship between shared leadership and employee adaptive performance. Future research may consider other underling mechanisms in the relationship between shared leadership and employee adaptive performance (e.g., team-level mediators). For example, it will be interesting to determine whether or not shared leadership influences employee adaptive performance by changing the team environment (e.g., team learning, etc.).

In addition, shared leadership was found to affect team-level capabilities (e.g., team reflexivity). Although prior research has revealed that other leadership styles (e.g., authentic leadership and transformational leadership) lead to team reflexivity, our research pioneers in demonstrating shared leadership can also exert such effect. Future research can examine the effect of shared leadership on other team-level capabilities or cognitive states (e.g., team creativity). In addition, future research may consider examining how shared leadership influence team level employee performance through the mediating roles of team level mediators. The current study focuses on the Chinese context where collectivistic and high-power distance value orientation values dominate. Future research on shared leadership should take cultural elements into consideration to uncover any possible moderators that may change the strength of the proposed relationships. For example, a cross-cultural study comparing the effects of shared leadership with both eastern and western contexts may yield fruitful results. In particular, power distance and uncertainty avoidance value orientations may alter the strength of the proposed relationships. One may anticipate that the impacts of shared leadership may be stronger for those who have low power distance and low uncertainty avoidance.

\subsection{Practical Implications}

Our research offers important practical implications for the tourism industry. First, tourism managers should take more initiatives in pursuing non-traditional leaderships such as shared leadership. Our research finding provides an alternative leadership style in addition to those leaderships that have been found useful in generating positive consequences (e.g., transformational leadership, authentic leadership). Shared leadership can mitigate the weaknesses of traditional vertical leadership and can be more effective in responding to rapid environmental changes $[8,63]$. This is very important for the hotel industry that is facing challenges brought by changing customer preferences, new generation employee groups and rapidly developing technologies. As the new generation employees have a strong desire to actively participate in management and operations instead of simply performing their assigned duties, it is crucial for the companies to get them involved in management practice through shared leadership. 
Thus, a supporting mechanism and training on leadership skills are more appropriate, as it can enhance employees' likelihood of engaging in team leadership. Shared leadership is thus not only a kind of leadership skill, but also an important management method to motivate the new generation employees, who are the main body in the workplace, from the bottom of their hearts. Employees who are really motivated can release the maximum value and reward companies with great productivity. In addition, training and team-building activities should be tailored to enhancing employees' sense of belonging to the organizations so that they can become more proactive in participating in collective leadership [63]. For example, organizing outdoor team-building activities such as hiking, and camping may strengthen the influence of shared leadership on team reflexivity as employees may get more inspirations from outside. The establishment of highly shared leadership teams can enable organizations to respond to the dynamic competitive environment more flexibly [10].

Second, hospitality firms should encourage employees to actively reflect and comment on team goals and strategies by reflecting upon past experiences and lessons. In the context of a constantly changing external environment, it is crucial for hospitality managers to keep reflecting on the organizational goals and strategies and take necessary and immediate actions accordingly. As a result, a supportive and open discussion environment should be ensured to induce team reflexivity. In particular, the management team may consider using a variety of platforms for discussion and reflection. For example, as social media has become so popular and widely used especially among the young generations, chatting groups within social media can be developed for different teams to promote both formal and informal communication. Therefore, a more open and efficient communication platform may strengthen the relationship between shared leadership and team reflexivity. The power of such a social media platform to induce more team reflexivity is to be enhanced. In addition, the necessary information should be disclosed to employees for discussion, and a progressive and stage-wise review of team goals and performance is encouraged. Releasing useful information through different platforms in a timely manner is needed.

Third, managers may review their company policies to ensure an active and assured environment for those who have the motivation to take proactive actions. For example, supervisors or managers can evaluate each employee's participation in team reflections and/or team decision making and offer incentives accordingly. This is especially important to countries where employees are traditionally less willing to express their own opinions. Employees who provide useful insights or suggestions during team reflection or take proactive action to improve their performance should be acknowledged and even rewarded. This may magnify the effect of shared leadership on proactive behavior.

Finally, in China, it was found that traditional Chinese leadership (i.e., authoritarian leadership) negatively influences employees' voice behavior [64]. However, not much research endeavor has been made to identify other non-traditional leaderships that may produce positive employee outcomes in China. Our research findings provide implications to resolve the problem in that Chinese managers may consider gradually change their traditional leadership to shared leadership.

\section{Conclusions and Future Research}

With the slowdown of global economic growth, the environment turbulence of the hospitality industry urges managers to undertake organizational transformation to make a timely response and thus sustain competitive advantages. Companies that fail to make the corresponding transformation, particularly leadership style, may be under the risk of losing human capital. The young generation employees may prefer shared leadership over the traditional leadership styles, and they may be more willing to take initiatives to lead the teams. Recent years have witnessed a trend to study non-traditional leadership styles and their influence on employee behavior and performance, yet, investigations into shared leadership and its consequences at both individual and team level remains scant in the leadership literature. The present study makes contributions to this line of research. Our study revealed that shared leadership influences an employee's adaptive performance through the mediating role of proactive behavior. This underlying mechanism is newly uncovered. Second, to the best of our 
knowledge, the present study pioneered in discovering the team reflexivity as a team-level consequence of shared leadership. Shared leadership contributes to the formation of an organization's learning climate, leading to enhanced reflections upon team goals and strategies (i.e., team reflexivity).

Hospitality managers should pay attention to the important roles that their leadership style plays in influencing firm performance. Particularly, hospitality managers should not only adapt to the rapidly changing environment with their leadership styles but also help to nurture a supportive environment to facilitate team reflexivity. These practices may help organizations maximize the value of their valuable internal resource. Shared leadership also has its values and implications for the industry. In today's hospitality industry, customers have exhibited a much higher expectation of service than before, and their needs have become more and more diversified than ever. The unprecedented success of sharing economy (e.g., AirBnB) well exemplified the changes in customer preferences and expectations [65]. Customers may expect service employees to show their initiatives and innovative ideas to solve problems and co-create a unique experience. This requires service employees to actively participate in management practice and share leadership responsibility so as to cope with such changes. In this regard, shared leadership is very likely to play a more and more important role in the hospitality industry in the future.

Although our study contributes to the literature, there are some limitations that should be addressed. First, as it was a cross-sectional study, although being a multi-level study, the causal relationships should be interpreted with caution. Future research can consider measuring shared leadership and its consequences at different time points and from different data sources. For example, shared leadership can be measured at time 1, and mediating variables and dependent variables at time 2. In addition, employee performance and employee behavior can be measured by their supervisors to minimize any possible subjective bias. Second, our findings may not be generalizable to other cultures since our samples are acquired just from the hotel industry in China. There may be sampling bias. Future research could consider selecting more diverse and representative samples from different cultures. A cross-cultural comparison study, particularly focusing on some cultural dimensions (e.g., individualism vs. collectivism, power distance, etc.), may yield interesting results. Third, other individual characteristic variables were not included (e.g., personality, cognitive capability, proactivity), as they were not the focus of our study. These variables may serve as control variables in future research.

Author Contributions: H.F. is responsible for the whole research project design, research conceptualization and proofreading of the manuscript, B.H.Y. handled data analysis and wrote the manuscript; X.X. assisted in data collection and writing. All authors have read and agreed to the published version of the manuscript.

Funding: This study was funded by the National Natural Science Foundation of China (grant number: 71772192 and grant number: 71402195).

Conflicts of Interest: The author(s) declared no potential conflict of interest with respect to the research, authorship, and/or publication of this article.

\section{Appendix A. Questionnaire Items}

\section{Appendix A.1. Shared Leadership}

1. In order to improve their work performance, colleagues can evaluate each other's work.

2. Colleagues are free to throw down gauntlet to other people's thoughts or ideas.

3. In order to make the work more efficient, colleagues are free to evaluate each other's deficiencies and weaknesses.

4. Our team attaches great importance to the contributions our teammates made.

5. Our team really cares about the welfare of the members.

6. Our team is very concerned about whether or not members of our team are satisfied with their jobs.

7. Our team cares about our teammates very much. 
8. In general, our team members know clearly about whether our team is satisfied with our jobs.

9. Members of our team know clearly about the problems and needs of team work.

10. Our team knows clearly about the potential of the members.

11. Out team will use power to help members solve important hurdles.

12. Our team will sacrifice their own interest to help members get rid of the difficulties.

13. We all trust our team, and we will support the decisions the team made even without our presence.

14. Our team and members have good relationships with each other.

Appendix A.2. Team Reflexivity

1. In this team we often review the feasibility of our objectives

2. In this team we often discuss the methods used to get the job done

3. In this team we regularly discuss whether we are working effectively together

4. In this team we modify our objectives in light of changing circumstances

5. In our team we often review our approach to getting the job done

\section{Appendix A.3. Proactive Behavior}

1. Initiated better ways of doing your core tasks

2. Come up with ideas to improve the way in which your core tasks are done

3. Made changes to the way your core tasks are done

\section{Appendix A.4. Adaptive Performance}

1. Adapted well to changes in core tasks

2. Coped with changes to the way you have to do your core tasks

3. Learned new skills to help you adapt to changes in your core tasks

\section{References}

1. Kulkarni, S.P.; Ramamoorthy, N. Commitment, flexibility and the choice of employment contracts. Hum. Rel. 2005, 58, 741-761. [CrossRef]

2. Carson, J.B.; Tesluk, P.E.; Marrone, J.A. Shared leadership in teams: An investigation of antecedent conditions and performance. Acad. Manag. J. 2007, 50, 1217-1234.

3. Pearce; Craig, L. The future of leadership: Combining vertical and shared leadership to transform knowledge work. Acad. Manag. Exe. 2004, 18, 47-57.

4. Drescher, M.A.; Korsgaard, M.A.; Welpe, I.M.; Picot, A.; Wigand, R.T. The dynamics of shared leadership: Building trust and enhancing performance. J. Appl. Psychol. 2014, 99, 771-783. [CrossRef]

5. Ensley, M.D.; Hmieleski, K.M.; Pearce, C.L. The importance of vertical and shared leadership within new venture top management teams: Implications for the performance of startups. Lead. Q. 2006, 17, 217-231. [CrossRef]

6. Hoch, J.E.; Kozlowski, S.W.J. Leading virtual teams: Hierarchical leadership, structural supports, and shared team leadership. J. Appl. Psychol. 2014, 99, 390-403. [CrossRef]

7. Wu, C.M.; Chen, T.J. Collective psychological capital: Linking shared leadership, organizational commitment, and creativity. Int. J. Hosp. Manag. 2018, 74, 75-84. [CrossRef]

8. Liu, S.; Hu, J.; Li, Y.; Wang, Z.; Lin, X. Examining the cross-level relationship between shared leadership and learning in teams: Evidence from China. Lead. Q. 2014, 25, 282-295. [CrossRef]

9. Wang, D.; Waldman, D.A.; Zhang, Z. A meta-analysis of shared leadership and team effectiveness. J. Appl. Psychol. 2014, 99, 181-198. [CrossRef]

10. Pearce, C.L.; Conger, J.A. Shared Leadership: Reframing the Hows and Whys of Leadership; Sage Publications: Thousand Oaks, CA, USA, 2003.

11. West, M.A. Reflexivity and work group effectiveness: A conceptual integration [A]. In Handbook of Work Group Psychology; West, M.A., Ed.; John Wiley \& Sons: Chichester, UK, 1996; pp. 555-579. 
12. Schippers, M.; Den Hartog, D.N.; Koopman, P.L.; Knippenberg, D.L.V. The role of transformational leadership in enhancing team reflexivity. Hum. Rel. 2008, 61, 1593-1616. [CrossRef]

13. Mathieu, J.E.; Kukenberger, M.R.; D'Innocenzo, L.; Reilly, G. Modeling reciprocal team cohesion-performance relationships, as impacted by shared leadership and members' competence. J. Appl. Psychol. 2015, 100, 713-734. [CrossRef] [PubMed]

14. Parker, S.K.; Williams, H.M.; Turner, N. Modeling the antecedents of proactive behavior at work. J. Appl. Psychol. 2016, 91, 636-652. [CrossRef] [PubMed]

15. Kanfer, R.; Wanberg, C.R.; Kantrowitz, T.M. Job search and employment: A personality-motivational analysis and meta-analytic review. J. Appl. Psychol. 2011, 86, 837. [CrossRef]

16. Erez, A.; Lepine, J.A.; Elms, H. Effects of rotated leadership and peer evaluation on the functioning and effectiveness of self-managed teams: A quasi-experiment. Per. Psychol. 2002, 55, 929-948. [CrossRef]

17. Mehraet, A.; Smith, B.; Dixon, A.; Robertson, B. Distributed leadership in teams: The network of leadership perceptions and team performance. Lead. Q. 2006, 17, 232-245. [CrossRef]

18. Ramthun, A.J.; Matkin, G.S. Multicultural shared leadership: A conceptual model of shared leadership in culturally diverse teams. J. Lead. Organiz. Stud. 2012, 19, 303-314. [CrossRef]

19. Chen, G.; Bliese, P.D. The role of different levels of leadership in predicting self-efficacy and collective efficacy: Evidence for discontinuity. J. Appl. Psychol. 2002, 87, 546-556. [CrossRef]

20. Hoch, J.E.; Dulebohn, J.H. Team personality composition, emergent leadership and shared leadership in virtual teams: A theoretical framework. Hum. Res. Manag. Rev. 2017, 27, 678-693. [CrossRef]

21. Chen, G.; Tjosvold, D. Shared rewards and goal interdependence for psychological safety among departments in China. Asia Pac. J. Manag. 2012, 29, 433-452. [CrossRef]

22. Pearce, C.L.; Sims, H.P., Jr. Vertical versus shared leadership as predictors of the effectiveness of change management teams: An examination of aversive, directive, transactional, transformational, and empowering leader behaviors. Gro. Dyn. Res. Pra. 2002, 6, 172-197. [CrossRef]

23. Hofstede, G.; Hofstede, G.J. Cultures and Organizations: Software of the Mind, 3rd ed.; Mcgraw-Hill: New York, NY, USA, 2005.

24. Ishikawa, J. Transformational leadership and gatekeeping leadership: The roles of norm for maintaining consensus and shared leadership in team performance. Asia Pac. J. Manag. 2012, 29, 265-283. [CrossRef]

25. Uhl-Bien, M.; Marion, R.; McKelvey, B. Complexity leadership theory: Shifting leadership from the industrial age to the knowledge era. Lead. Q. 2007, 18, 298-318. [CrossRef]

26. Detert, J.R.; Burris, E.R. Leadership behavior and employee voice: Is the door really open? Acad. Manag. J. 2007, 50, 869-884. [CrossRef]

27. Hmieleski, K.M.; Cole, M.S.; Baron, R.A. Shared authentic leadership and new venture performance. J. Manag. 2011, 38, 1476-1499. [CrossRef]

28. Bergman, J.Z.; Rentsch, J.R.; Small, E.E.; Davenport, S.W.; Bergman, S.M. The shared leadership process in decision-making teams. J. Soc. Psychol. 2012, 152, 17-42. [CrossRef]

29. Parker, S.K.; Collins, C.G. Taking stock: Integrating and differentiating multiple proactive behaviors. J. Manag. 2010, 36, 633-662. [CrossRef]

30. Crant, J.M. Proactive behavior in organizations. J. Manag. 2000, 26, 435-462. [CrossRef]

31. Frese, M.; Fay, D. Personal initiative: An active performance concept for work in the 21st century. Res. Organiz. Behav. 2001, 23, 133-187. [CrossRef]

32. Grant, A.M.; Ashford, S.J. The dynamics of proactivity at work. Res. Organiz. Behav. 2008, 28, 3-34. [CrossRef]

33. Parker, S.K.; Bindl, U.K.; Strauss, K. Making things happen: A model of proactive motivation. J. Manag. 2010, 36, 827-856. [CrossRef]

34. Pearce, C.L.; Manz, C.C.; Sims, H.P. The roles of vertical and shared leadership in the enactment of executive corruption: Implications for research and practice. Lead. Q. 2008, 19, 353-359. [CrossRef]

35. Blau, P.M. Exchange and Power in Social Life; John Wiley and Sons: New York, NY, USA, 1964.

36. Erdogan, B.; Enders, J. Support from the top: Supervisors' perceived organizational support as a moderator of leader-member exchange to satisfaction and performance relationships. J. Appl. Psychol. 2007, 92, 321-330. [CrossRef] [PubMed]

37. Tse, H.H.M.; Huang, X.; Lam, W. Why does transformational leadership matter for employee turnover? a multi-foci social exchange perspective. Lead. Q. 2013, 24, 763-776. [CrossRef] 
38. Richard, O.C.; Ismail, K.M.; Bhuian, S.N.; Taylor, E.C. Mentoring in supervisor-subordinate dyads: Antecedents, consequences, and test of a mediation model of mentorship. J. Bus. Res. 2015, 62, 1110-1118. [CrossRef]

39. Masterson, S.S.; Lewis, K.; Goldman, B.M.; Taylor, M.S. Integrating justice and social exchange: The differing effects of fair procedures and treatment on work relationships. Acad. Manag. J. 2000, 43, 738-748.

40. Walker, J. Developing a shared leadership model at the unit level. J. Per. Neo. Nurs. 2001, 15, 26. [CrossRef]

41. Jundt, D.; Shoss, M.K.; Huang, J.L. Individual adaptive performance in organizations: A review. J. Organiz. Beh. 2014, 6, 53-71. [CrossRef]

42. Chan, D. Understanding adaptation to changes in the work environment: Integrating individual difference and learning perspectives. Res. Per. Hum. Res. Manag. 2000, 18, 1-42.

43. Griffin, M.A.; Neal, A.; Parker, S.K. A new model of work role performance: Positive behavior in uncertain and interdependent contexts. Acad. Manag. J. 2007, 50, 327-347. [CrossRef]

44. Griffin, M.; Parker, S.; Mason, C. Leader vision and the development of adaptive and proactive performance: A longitudinal study. J. Appl. Psychol. 2010, 95, 174-182. [CrossRef] [PubMed]

45. Charbonnier-Voirin, A.; El Akremi, A.; Vandenberghe, C. A multilevel model of transformational leadership and adaptive performance and the moderating role of climate for innovation. Gro. Organiz. Manag. 2010, 35, 699-726. [CrossRef]

46. Griffin, B.; Hesketh, B. Adaptable behaviors for successful work and career adjustment. Aus. J. Psychol. 2003, 55, 65-73. [CrossRef]

47. Kozlowski, S.W.J.; Gully, S.M.; Brown, K.G.; Salas, E.; Smith, E.M.; Nason, E.R. Effects of training goals and goal orientation traits on multidimensional training outcomes and performance adaptability. Organiz. Beh. Hum. Dec. Pro. 2001, 85, 1-31. [CrossRef] [PubMed]

48. Wyer, R.S.; Srull, T.K. Human cognition in its social context. Psychol. Rev. 1986, 93, 322-359. [CrossRef] [PubMed]

49. Bandura, A. Social Foundations of Thought and Action: A Social Cognitive Theory; Prentice-Hall: Upper Saddle River, NJ, USA, 1987.

50. Lyubovnikova, J.; Legood, A.; Turner, N.; Mamakouka, A. How authentic leadership influences team performance: The mediating role of team reflexivity. J. Bus. Eth. 2017, 141, 1-12. [CrossRef]

51. Schippers, M.C.; West, M.A.; Dawson, J.F. Team reflexivity and innovation: The moderating role of team context. J. Manag. 2010, 41, 769-788. [CrossRef]

52. Tjosvold, D.; Tang, M.; West, M.A. Reflexivity for team innovation in China: The contribution of goal interdependence. Gro. Organiz. Manag. 2004, 29, 540-559. [CrossRef]

53. De Jong, B.A.; Elfring, T. How does trust affect the performance of ongoing teams? The mediating role of reflexivity, monitoring, and effort. Acad. Manag. J. 2010, 53, 535-549. [CrossRef]

54. Soriano, M.Y.; Foxall, G.R. A Spanish translation of Mehrabian and Russell's emotionality scales for environmental consumer psychology. J. Con. Behav. 2002, 2, 23-36. [CrossRef]

55. Gerbing, D.W.; Anderson, J.C. An updated paradigm for scale development incorporating unidimensionality and its assessment. J. Mark. Res. 1988, 25, 186-192. [CrossRef]

56. Hair, J.F.; Black, W.C.; Babin, B.J.; Anderson, R.E. Multivariate Data Analysis: A Global Perspective; Pearson Prentice Hall: Upper Saddle River, NJ, USA, 2010.

57. Kline, R.B. Principles and Practice of Structural Equation Modeling; Guilford: New York, NY, USA, 2005.

58. Hair, J.F., Jr.; Black, W.C.; Babin, B.J.; Anderson, R.E.; Tatham, R.L. Multivariate Data Analysis; Pearson Prentice Hall: New York, NY, USA, 2006.

59. Bliese, P.D. Within-group agreement, non-independence, and reliability: Implications for data aggregation and analysis. In Multilevel Theory, Research, and Methods in Organizations: Foundations, Extensions, and New Directions; Klein, K.J., Kozlowski, S.W.J., Eds.; Jossey-Bass: San Francisco, CA, USA, 2000; pp. 349-381.

60. James, L.R.; Demaree, R.G.; Wolf, G. Estimating within-group interrater reliability with and without response bias. J. Appl. Psychol. 1984, 69, 85-98. [CrossRef]

61. Baron, R.M.; Kenny, D.A. The moderator-mediator variable distinction in social psychological research: Conceptual, strategic, and statistical considerations. J. Pers. Soc. Psychol. 1986, 51, 1173-1182. [CrossRef] [PubMed]

62. Gronn, P. Distributed leadership as a unit of analysis. Lead. Q. 2002, 13, 423-451. [CrossRef] 
63. Chiaburu, D.S.; Harrison, D.A. Do peers make the place? Conceptual synthesis and meta-analysis of coworker effects on perceptions, attitudes, OCBs, and performance. J. Appl. Psychol. 2008, 93, 1082. [CrossRef] [PubMed]

64. Li, Y.; Sun, J.M. Traditional Chinese leadership and employee voice behavior: A cross-level examination. Lead. Q. 2015, 26, 172-189. [CrossRef]

65. Guttentag, D.; Smith, S.; Potwarka, L.; Havitz, M. Why Tourists Choose Airbnb: A Motivation-Based Segmentation Study. J. Travel. Res. 2017, 57, 342-359. [CrossRef] 